\title{
The efficacy of Propionibacterium jensenii 702 to stimulate a cell-mediated response to orally administered soluble Mycobacterium tuberculosis antigens using a mouse model
}

\author{
Michelle C. ADAMS ${ }^{\mathrm{a} *}$, Melanie L. LEAN ${ }^{\mathrm{a}}$, Nola C. HITCHICK ${ }^{\mathrm{a}}$, \\ Kenneth W. BEAGLEYb \\ a School of Applied Sciences, University of Newcastle, Ourimbah, NSW, 2258, Australia \\ b School of Biomedical Sciences, University of Newcastle, Newcastle, NSW, 2300, Australia
}

\begin{abstract}
Mucosal vaccination using adjuvant protein vaccines may offer a novel approach for tuberculosis. To date, however, development of such a vaccine has been considered unlikely due to the inability to identify a safe adjuvant that stimulates an appropriate immune response. This study was undertaken to determine the potential of a dairy propionibacteria, P. jensenii strain 702 (PJ702), to act as an adjuvant when co-administered orally with soluble tuberculosis protein to mice. The efficacy of the PJ702 to act as an adjuvant was assessed by comparison with cholera toxin. C57 mice were orally immunized with Mycobacterium tuberculosis short-term culture filtrate protein (STCF) $(200 \mu \mathrm{g})$ with either PJ702 $\left(10^{8} \mathrm{cfu}\right)$ or cholera toxin $(10 \mu \mathrm{g})$ in a total volume of $100 \mu \mathrm{L}$. A control group was given PJ702 $10^{8} \mathrm{cfu}$ alone. Each mouse (eight per group) was vaccinated weekly over a 21-day period. At day 25 the mice were sacrificed, spleens were collected and lymphocyte cultures prepared. After stimulation with STCF $(2.5 \mu \mathrm{g})$, cell proliferation was measured by ${ }^{3} \mathrm{H}$ thymidine uptake, and the cytokines, IL-4 and IFN- $\gamma$, by ELISA. A significantly higher T-cell proliferation was observed for the group given the vaccine containing PJ702, compared to both the control group and the group given the vaccine containing cholera toxin $(P<0.05)$. The predominant cytokine produced from all groups was IFN- $\gamma$. These results indicate potential for future development of an oral tuberculosis vaccine, and also identify PJ702 as a potential living vaccine vector that could be applied to a number of mucosally transmitted diseases.
\end{abstract}

Propionibacterium / tuberculosis / vaccine / cell-mediated / adjuvant

Résumé - Efficacité de Propionibacterium jensenii 702 à stimuler la réponse des cellules aux antigènes solubles de Mycobacterium tuberculosis administrés oralement à des souris. Des vaccins administrés par voie orale, comprenant un antigène et un adjuvant protéique, constituent une nouvelle approche pour lutter contre la tuberculose. Â ce jour, le développement d'un tel vaccin n'a cependant pas avancé en raison de l'absence d'adjuvant approprié, qui permettrait une stimulation de la réponse immunitaire efficace, et sans risque. Cette étude a été menée pour déterminer le potentiel d'une bactérie propionique d'origine laitière, Propionibacterium jensenii (PJ702), à servir d'adjuvant, quand co-administré par voie orale à des souris avec les protéines solubles de la tuberculose. L'efficacité de PJ702 en tant qu'adjuvant a été évaluée en comparaison à la toxine cholérique. Un filtrat (appelé STCF) contenant des protéines d'une culture à court terme de Mycobacterium tuberculosis $(200 \mu \mathrm{g})$ a été administré par voie orale à des souris de type $\mathrm{C} 57$, conjointement avec

\footnotetext{
* Corresponding author: Michelle.Adams@newcastle.edu.au
} 
PJ702 (10 8 ufc) ou avec la toxine cholérique $(10 \mu \mathrm{g})$, dans un volume total de $100 \mu \mathrm{L}$. Un groupe témoin a reçu PJ702 seul ( $10^{8} \mathrm{ufc}$ ). Chaque souris ( 8 par groupe) a été vaccinée hebdomadairement sur une période de 21 jours. Le $25^{\mathrm{e}}$ jour, les souris ont été sacrifiées, la rate prélevée et les lymphocytes mis en culture. Après stimulation par STCF $(2,5 \mu \mathrm{g})$, la prolifération cellulaire a été évaluée par mesure de l'incorporation de la thymidine ${ }^{3} \mathrm{H}$; la production des cytokines, IL-4 et IFN- $\gamma$, a été évalué par ELISA. Une prolifération des cellules T significativement plus élevée a été observée dans le groupe recevant le vaccin contenant PJ702, par rapport au groupe témoin, ou au groupe recevant le vaccin contenant la toxine cholérique $(P<0,05)$. La cytokine majoritairement produite dans tous les groupes était IFN- $\gamma$. Ces résultats montrent le potentiel de développement d'une stratégie de vaccination orale contre la tuberculose. PJ702 est identifié comme un vecteur potentiel pour délivrer des vaccins vivants, applicable aux différents types de maladies d'origine mucosale.

\section{Propionibacterium / tuberculose / vaccin / réponse immunitaire / adjuvant}

\section{INTRODUCTION}

By 2004, the number of deaths from tuberculosis (TB) is expected to reach 4 million per annum [39], making it the highest cause of death from a single infectious agent in the world today [38]. The majority of tuberculosis cases occur in the world's poorest nations [22], however there is a resurgence of TB throughout the developed world, and the hope of eradication is remote without the development of a new tuberculosis vaccine. The current vaccine, Bacille Calmette-Guerin (BCG), has an efficacy range of 0 to $80 \%[6,17]$, and it is estimated that the development of a new vaccine with only $50 \%$ efficacy could prevent 9 million deaths from tuberculosis by the year 2030 [29].

Since 1993, when the World Health Organisation (WHO) declared TB to be a global health emergency [2] a monumental effort was directed towards the development of a new TB vaccine, with limited success. Almost all of these vaccines have been designed for parenteral administration. The concept of an oral vaccine had been previously considered, however when children administered oral Mycobacterium bovis BCG demonstrated low rates of delayed-type hypersensitivity conversion and occasional development of cervical lymphadenitis, the concept was abandoned [16]. A recent study by Doherty et al. (2002) examined the use of a subunit oral vaccine composed proteins from M. tuberculosis [10]. The results were disappointing, in that the interferon gamma (IFN- $\gamma$ ) produced, which is essen- tial in a TB vaccine [28], was no different between the treated and naive animals. It was concluded from this study that oral vaccination using $M$. tuberculosis did not efficiently prime immune responses [10]. In 2003, Aldwell et al. revisited the use of orally administered $M$. bovis BCG using a novel lipid formulation as an adjuvant, stimulating protective immune responses and protection against aerosol challenge with M. bovis [3]. He concluded that lipid based orally delivered mycobacterial vaccines may be a safe and effective means of controlling TB in humans and animals.

The concept of an oral vaccine for TB has many advantages, in particular its potential ability to trigger a mucosal immune response [31] that is important in TB immunity [32]. In addition they are easy to administer, inexpensive and reduce the risk of disease transmission through contaminated syringes, all of which are particularly important for application in developing countries. The risk of using a live vaccine, as in the Aldwell et al. (2003) study [3], however is the association between tuberculosis and HIV infection. Currently, 8$10 \%$ of all tuberculosis cases worldwide are related to HIV infection, although the situation in certain developing countries is definitely worse [39]. With 20 million people in Sub-Saharan Africa alone being infected with HIV, and $50 \%$ also being co-infected with TB [14] the use of a live vaccine may push the limit between disease protection and infection.

One of the major difficulties in the development of an oral vaccine is selection of a 
safe adjuvant for human consumption. The commercially available cutaneous strain of Propionibacterium, P. acnes $\left(\right.$ Eqstim $\left.^{\mathrm{R}}\right)$, has been long recognized as a non-specific immune stimulant in the equine industry [15]. Immune enhancement by Eqstim ${ }^{R}$ has been demonstrated by a number of immune markers including the amplification of interferon production, and increased macrophage and lymphocyte function [15]. Higher levels of IFN- $\gamma$ production have been observed in rabies vaccinated mice when given inactivated $P$. acnes compared to mice without $P$. acnes or other potential immunstimulants including avridine and BCG [25]. The mechanism of action of $P$. acnes appears to be both on the macrophages and natural killer cells [25, 26]. Similar immune stimulation is required for immunity to tuberculosis, and leads to a potential role of Propionibacterium sp. as an adjuvant for such a vaccine. $P$. acnes is however, a potential pathogen, and efficacy to date has been demonstrated by inactivated organism given via either the intra-venous or intra-peritoneal route [15, $25,26]$.

This study examined a recently identified potential probiotic strain of Propionibacterium as the adjuvant for an oral tuberculosis vaccine, Propionibacterium jensenii 702 (PJ702) [1, 18-20]. P. jensenii belongs to the dairy propionibacteria group, which have a long history of safe use in dairy food products. PJ702 therefore has an advantage over P. acnes, in that oral administration is likely to be safe, and therefore it may be applicable as a living vaccine vector. In addition, a particular quality of PJ702 is its ability to adhere to human gastrointestinal epithelial cells [18]. This is not a common feature amongst dairy propionibacteria, but essential if to be used as an adjuvant [30]. It is well known that certain orally administered probiotic bacteria can induce local and systemic immune responses [12], and have been shown to induce strong IFN- $\gamma$, Interleukin (IL)-12 [27] and tumour necrosis factor (TNF- $\alpha$ ) [24] cytokine production. Therefore the potential to use a non-pathogenic strain of Propionibacterium as an oral adjuvant and potential living vaccine vector is a novel approach to tuberculosis and possibly other vaccination.

\section{MATERIALS AND METHODS}

\subsection{Antigen preparation}

Mycobacterium tuberculosis H37Rv strain (ATCC 27294) was used in the antigen preparation. The culturing of the bacteria is a modification of the method described by Anderson et al. [5].

Briefly, M. tuberculosis H37Rv strain (ATCC 27294) grown in air at $37{ }^{\circ} \mathrm{C}$ on Lowenstein Jensen (LJ) slopes (bio Mérieux, Baulkham Hills, Australia) was transferred onto a sterile $0.45-\mu \mathrm{m}$ cellulose ester membrane (Advantec MFS, Bonnet Equipment, Caringbah, Australia). The membrane disc was floated on the surface of Modified Sauton's Medium (MSM), and incubated at $37^{\circ} \mathrm{C}$ in air for 2 weeks. The bacteria was then separated from the membrane and transferred to a fresh Modified Sauton's Medium. Subcultures were made every 4-7 days depending on the extent of bacterial growth.

Once sufficient growth of the $M$. tuberculosis was observed, the mass of cells were removed from the MSM, and the remaining culture medium was sterile filtered $(0.22 \mu \mathrm{m})$ (Sartorius Ministart filter, Sotorius, East Oakleigh, Australia) to collect short-term culture filtrate (STCF) protein. This protein was then concentrated by stepwise filtering using an Ultrafiltration Cell (Amicon, Bonnet Equipment, Caringbah, Australia) using a $10 \mathrm{~kg} \cdot \mathrm{mol}^{-1}$ followed by a $3 \mathrm{~kg} \cdot \mathrm{mol}^{-1}$ pore size filter (Amicon).

The concentration of protein for STCF antigen was determined by the Bio-Rad Protein Assay. Briefly, antigen was diluted $1: 5,1: 10$ and $1: 20$ in PBS and $10 \mu \mathrm{L}$ of these dilutions, controls and standards were added in duplicate to designated wells of a microtitre plate (Nunc, Medos Company Pty Ltd., Mt. Waverly, Australia). Then 100 L of diluted dye reagent (Bio-Rad, Regents Park, Australia) was added to each well and the plate was left to incubate at room temperature for a minimum of $5 \mathrm{~min}$ and a maximum of $1 \mathrm{~h}$. The absorbance was then read at $595 \mathrm{~nm}$ (Bio-Rad Microplate Reader Model 550). Raw data was automatically processed through the Bio-Rad Microplate Manager computer program (Version 5.0.1), 
producing a standard curve and calculating the protein concentration of the samples.

\subsection{Propionibacterium jensenii 702 (PJ702) adjuvant preparation}

Strain $P$. jensenii 702 was grown anaerobically in $20 \mathrm{McCartney}$ bottles, each containing $20 \mathrm{~mL}$ of Sodium Lactate Broth (SLB) $\left(10 \mathrm{~g} \cdot \mathrm{L}^{-1}\right.$ tryptone, $10 \mathrm{~g} \cdot \mathrm{L}^{-1}$ yeast extract, $10 \mathrm{~g} \cdot \mathrm{L}^{-1}$ sodium lactate, $0.25 \mathrm{~g} \cdot \mathrm{L}^{-1}$ $\mathrm{K}_{2} \mathrm{HPO}_{4}, 0.5 \mathrm{~g} \cdot \mathrm{L}^{-1} \mathrm{MnSO}_{4}, \mathrm{pH} 7.0$ ), at $30^{\circ} \mathrm{C}$ for $3 \mathrm{~d}$. The cultures were then transferred to two sterile $250 \mathrm{~mL}$ centrifuge tubes. The bacterial cells were collected by centrifugation $(3500 \times g, 5 \mathrm{~min})$. The supernatants were discarded and the cell pellets were washed twice in $60 \mathrm{~mL}$ of $8.5 \mathrm{~g} \cdot \mathrm{L}^{-1}$ $\mathrm{NaCl}$ (Sigma, Sydney, Australia), with centrifugation $(3500 \times g, 5 \mathrm{~min})$ between each wash. Bacteria cells were then resuspended in $30 \mathrm{~mL}$ of $8.5 \mathrm{~g} \cdot \mathrm{L}^{-1} \mathrm{NaCl}$ and aliquots $(3.5 \mathrm{~mL})$ of the bacteria suspension were dispensed into $5 \mathrm{~mL}$ sterile tubes and stored at $4{ }^{\circ} \mathrm{C}$ for up to $7 \mathrm{~d}$. The viable cell counts of bacterial suspensions were tested by pour plate.

\subsection{Animals}

Female pathogen-free C57 mice, 8 to 12 weeks of age, were supplied by the University of Newcastle Animal Services. They were housed in standard caging, 4 mice per cage, at the David Maddison Building Animal House, University of Newcastle, Australia. The use of animals for this experiment was approved by the University of Newcastle Animal Care and Ethics Committee.

\subsection{Immunisation}

Mice were divided into 3 groups of 8 , 2 groups (Groups 1 and 2) were given daily supplements of approximately $10^{7} \mathrm{cfu} \cdot \mathrm{mL}^{-1}$ of P. jensenii 702 in fresh drinking water. All groups were given 3 oral vaccine doses 7 days apart. Group 1 was given $200 \mu \mathrm{g}$ STCF and $10^{8}$ colony forming units (cfu) PJ702; Group 2 was given $10^{8}$ cfu PJ702; and Group 3 given $200 \mu \mathrm{g}$ STCF and $10 \mu \mathrm{g}$ cholera toxin (CT) (Sigma), all in a total volume of $100 \mu \mathrm{L}$.

\subsection{Gastrointestinal survival of $P$. jensenii 702}

Faeces from each mouse were collected in $20 \mathrm{~mL}$ of $0.05 \mathrm{~mol} \cdot \mathrm{L}^{-1}$ sodium phosphate buffer $\mathrm{pH} \quad\left(0.05 \mathrm{~mol} \cdot \mathrm{L}^{-1} \quad \mathrm{NaH}_{2} \mathrm{PO}_{4}\right.$, $\left.0.05 \mathrm{~mol} \cdot \mathrm{L}^{-1} \mathrm{Na}_{2} \mathrm{HPO}_{4}, \mathrm{pH} 7.0\right)$ and stored at $4{ }^{\circ} \mathrm{C}$ for up to $24 \mathrm{~h}$ before testing. The faecal suspensions were prepared by stirring using a spatula and then being vortexed at a maximum setting for $10 \mathrm{~s}$ by a vortex mixer. Serial dilutions were made using $9 \mathrm{~mL}$ of half strength Wilkins-Chalgren Anaerobe Broth (WCAB) (Oxoid, West Heidelberg, Australia). Bacterial viable cell counts of mouse faeces were determined by the spread plate method. A given amount of each dilution $(0.1 \mathrm{~mL})$ was inoculated onto two sodium lactate agar (SLA) $\left(10 \mathrm{~g} \cdot \mathrm{L}^{-1}\right.$ tryptone, $10 \mathrm{~g} \cdot \mathrm{L}^{-1}$ yeast extract, $10 \mathrm{~g} \cdot \mathrm{L}^{-1}$ sodium lactate, $0.25 \mathrm{~g} \cdot \mathrm{L}^{-1} \mathrm{~K}_{2} \mathrm{HPO}_{4}, 0.5 \mathrm{~g} \cdot \mathrm{L}^{-1}$ $\mathrm{MnSO}_{4}, 15 \mathrm{~g} \cdot \mathrm{L}^{-1}$ agar, $\mathrm{pH} 7.0$ ) plates. After incubation at $30{ }^{\circ} \mathrm{C}$ anaerobically for $5 \mathrm{~d}$, typical colonies of dairy propionibacteria were counted.

\subsection{Lymphocyte cultures for T-cell proliferations}

Following euthanasia mice spleens of each group were pooled and homogenized by macerating the tissue through a finemesh stainless steel sieve. The tissue suspension was then centrifuged (Heraeus Megafuge 1.0R, Kendro Instruments Australia Pty Ltd, Lane Cove, Australia) at $1200 \mathrm{rpm}$ for $10 \mathrm{~min}$ at $4{ }^{\circ} \mathrm{C}$ and the supernatant removed. The spleen cell pellet was resuspended in $5 \mathrm{~mL}$ of Red Blood Cell Lysis Buffer $\left(8.3 \mathrm{~g} \cdot \mathrm{L}^{-1} \mathrm{NH}_{4} \mathrm{Cl}, 1.0 \mathrm{~g} \cdot \mathrm{L}^{-1}\right.$ $\mathrm{NaHCO}_{3}, 0.037 \mathrm{~g} \cdot \mathrm{L}^{-1}$ EDTA di-sodium salt, $\mathrm{pH}$ 7.35) and placed on ice for $5 \mathrm{~min}$. Then $5 \mathrm{~mL}$ of RPMI complete medium (500 mL RPMI [Trace Scientific], $5 \mathrm{~mL}$ $10000 \mathrm{U} \cdot \mathrm{mL}^{-1}$ Penicillin $/ 10 \mathrm{mg} \cdot \mathrm{mL}^{-1}$ Streptomycin, $5 \mathrm{~mL} 200 \mathrm{mmol} \cdot \mathrm{L}^{-1} \mathrm{~L}$-glutamine, $5 \mathrm{~mL} 5 \mathrm{~mol} \cdot \mathrm{L}^{-1}$ 2-Mercaptoethanol, $10 \mathrm{~mL} 1 \mathrm{~mol} \cdot \mathrm{L}^{-1}$ HEPES buffer, $50 \mathrm{~mL}$ heat inactivated foetal calf serum) was added and centrifuged for a further $10 \mathrm{~min}$ at $1200 \mathrm{rpm}$ at $4{ }^{\circ} \mathrm{C}$. The spleen cell pellet was washed 3 times with $10 \mathrm{~mL}$ RPMI complete medium and finally resuspended in 
$10 \mathrm{~mL}$ of RPMI complete medium at a concentration of $4 \times 10^{6}$ cells $\cdot \mathrm{mL}^{-1}$.

The cells were dispensed in quadruplicate in $100 \mathrm{~L}$ volumes into a 96-well plates containing $2.5 \mu \mathrm{g} \cdot \mathrm{mL}^{-1}$ of STCF in $100 \mu \mathrm{L}$ RPMI complete medium. Cultures were incubated in 5\% carbon dioxide $\left(\mathrm{CO}_{2}\right)$ at $37^{\circ} \mathrm{C}$ for $3 \mathrm{~d}$, at which time $10 \mu \mathrm{L}$ of [methyl$\left.{ }^{3} \mathrm{H}\right]$ thymidine tracer (Amersham, Castle Hill, Australia) diluted in complete RPMI was added to each well $(0.5 \mu \mathrm{Ci} /$ well $)$. The plates were incubated for a further $6 \mathrm{~h}$ before harvesting onto glass fibre filters (Packard Filtermate 196, Perkin Elmer Life Sciences (Australia) Pty Ltd, Rowville, Australia) and dried at $60^{\circ} \mathrm{C}$. Meltilex Scintillator wax (Wallac, Perkin Elmer Life Sciences (Australia) Pty Ltd, Rowville, Australia) was then melted onto the glass fibres, sealed in a sample bag, and read on a Liquid Scintillation and Luminescence Counter (TRILUX 1450 MicroBeta Perkin Elmer Life Sciences (Australia) Pty Ltd, Rowville, Australia).

\subsection{Lymphocyte cultures for cytokine analysis}

Interleukin 4 (IL-4) and Interferon Gamma (IFN- $\gamma$ ) were measured from spleen lymphocyte culture supernatant by ELISA (Pharmingen, BD Biosciences, North Ryde, Australia). Spleen cells were prepared as described above, and $0.5 \mathrm{~mL}$ of the final cell suspension was dispensed in duplicate into Multiwell tissue culture plates (Falcon, Becton Dickinson, BD Biosciences, North Ryde, Australia) and stimulated with $2.5 \mu \mathrm{g} \cdot \mathrm{mL}^{-1}$ STCF. The cultures were incubated for $72 \mathrm{~h}$ in $5 \%$ carbon dioxide at $37^{\circ} \mathrm{C}$. The supernatants from each well were then collected and stored at $-80{ }^{\circ} \mathrm{C}$ until required for testing.

\subsection{ELISA testing for IL-4 and IFN- $\gamma$}

Cytokines were measure using Pharmingen OptEIA Kits as per the manufactures instructions. Briefly, NUNC Immunosorbent multi-well plates were coated with $100 \mathrm{~L}$ of dilute capture antibody (Pharmingen), sealed and incubated overnight at $4{ }^{\circ} \mathrm{C}$. The plates were then washed 5 times with wash buffer (PBS, $0.5 \mathrm{~mL} \cdot \mathrm{L}^{-1}$ Tween
20), and then blocked with Assay Diluent (Pharmingen) at room temperature for $1 \mathrm{~h}$. Plates were then washed 5 times with wash buffer and $100 \mathrm{~L}$ of standard (Pharmingen) or sample were added in duplicate to appropriate wells and incubated for $2 \mathrm{~h}$ at room temperature. The plates were once again washed 5 times with wash buffer, and $100 \mu \mathrm{L}$ of Working Detector (Pharmingen) was added to each well, and the plate was incubated for a further hour at room temperature. After washing 10 times with 30-s soaks, $100 \mu \mathrm{L}$ of TMB substrate solution (Pharmingen) was added to each well, and the plate incubated at room temperature for 30 min in the dark. The reaction was stopped with $50 \mu \mathrm{L}$ of stop solution $\left(2 \mathrm{~mol} \cdot \mathrm{L}^{-1}\right.$ $\mathrm{H}_{2} \mathrm{SO}_{4}$ ). The resulting plates were immediately read on a Bio-Rad Microplate Reader (Model 550) at an absorbance of $450 \mathrm{~nm}$ and $570 \mathrm{~nm}$. The $570 \mathrm{~nm}$ reading subtracted from the $450 \mathrm{~nm}$ readings to give the final absorbance. Raw data was automatically processed through the Bio-Rad Microplate Manager computer program (Version 5.0.1), producing a standard curve and calculating final cytokine concentrations in picograms/ $\mathrm{mL}\left(\mathrm{pg} \cdot \mathrm{mL}^{-1}\right)$.

\subsection{Statistical analysis}

Statistical analyses of the results were performed using Microsoft Excel 2000. Single factor ANOVAs were performed on entire sets of raw data, and then a Student's t-test, two-tailed, assuming equal variance was used. A ' $P$ ' value of less than 0.05 was considered indicative of statistical significance between sets of data. Mean, standard deviation and all graphs were also generated in Microsoft Excel 2000.

\section{RESULTS AND DISCUSSION}

\subsection{Recovery of P. jensenii 702 from mice faeces}

Application of PJ702 as an oral adjuvant requires the bacterium to survive the gastrointestinal tract and successfully colonize the small intestine [13]. These traits have been demonstrated previously for PJ702 [1, 20]. In these studies it was possible to 
Table I. Viable counts of $P$. jensenii 702 in the faeces of mice during the 25-day study period.

\begin{tabular}{cccc}
\hline \multicolumn{4}{c}{ Plate count $\left(\mathrm{cfu} \cdot \mathrm{mL}^{-1}\right)$} \\
\hline Vaccine & \multicolumn{3}{c}{ Days } \\
\cline { 2 - 4 } group & 0 & 7 & 25 \\
\hline 1 & 0 & $1.25 \pm 0.50 \times 10^{6}$ & $1.60 \pm 0.55 \times 10^{6}$ \\
2 & 0 & 0 & $3.50 \pm 2.59 \times 10^{6}$ \\
3 & 0 & 0 & 0 \\
\hline
\end{tabular}

Group 1 = STCF/PJ702; Group 2 = PJ702; Group $3=\mathrm{STCF} / \mathrm{CT}$. Values are mean $\pm \mathrm{SD}(n=6-8)$. $\mathrm{cfu}=$ colony forming units.

achieve colonisation with PJ702 in rats using daily supplementation of drinking water, resulting in an average daily dosage rate of $10^{10} \mathrm{cfu}$ per rat, with measurable changes in blood parameters after 4 weeks [1]. The volume of water consumed by mice however is relatively low, and it was questionable whether water supplementation would be sufficient to establish background colonization. In addition, protocols using cholera toxin as the adjuvant for an oral TB protein vaccine had been previously established (unpublished data) using a total experimental period of 25 days. For these reasons, PJ702 treated mice were exposed to the probiotic daily through supplemented water, and by intragastric gavage, co-administered with the vaccine, 3 times 7 days apart. It was argued that through this approach adequate probiotic exposure would result, leading to a measurable effect on the immune stimulation within the study period. The normal presence of dairy propionibacteria, and its ability to survive in the mice gastrointestinal tract of mice, were then examined by the recovery of propionibacteria from the mouse faeces.

No dairy propionibacteria were observed in any mouse faeces sample prior to the introduction of the PJ702 to the mice, and only mice given the PJ702 demonstrated dairy propionibacteria in their faeces (Tab. I). The faecal isolation rate of PJ702 was less than and more variable to that previously observed in rats [20]. Faecal recovery of PJ702 was observed earlier for Group 1 (day 7) compared to Group 2 (day 25). This was likely due to the vaccine protein having some protection on PJ702 when the vaccine was administered into the stomach of the mouse. The protective value of co-administered substrates with probiotics has been well established in food studies $[7,8,19,35$, 40]. The mechanism of protection in most cases is due to either buffering or an increase in gut $\mathrm{pH}$ due to the administered substrate. Waterman et al. (1998) demonstrated that acid tolerance of Salmonella increases when inoculated onto the surface of ground beef [36]. Although it could be argued that fat has a role in this improved acid tolerance, the authors identify that the same protection is observed with boiled egg white, which contains low fat. It was suggested that the protein may in fact provide a significant role in the protection. In this study, some vaccine proteins may have adhered to PJ702, creating microenvironments protecting the bacteria during gastrointestinal transit. Further it is possible that the amino acid composition of the vaccine may have induced acid resistance in a similar way to what has been observed for some strains of Shigella flexneri and E. coli [36].

No significant difference was observed between the faecal propionibacteria counts between Groups 1 and 2 at day 25, primarily due to the large variation in counts between the mice. Regardless of this, the relatively low faecal isolation rate of PJ702 suggests the protective role of co-administered substrates with PJ702 will be important in its application as a living vaccine vector.

Although probiotics by definition are given orally, in respect to immune stimulation and the potential to overcome gut barriers, alternative administration should be considered. Seeger [33] reports that intranasal vaccination, when applied using lactobacilli as the vaccine vector, results in a better immune response than observed by oral exposure.

\subsection{T-cell proliferation}

An optimal adjuvant for a TB vaccine should favour the development of a cellmediated, IFN- $\gamma$ response $[2,11]$. Substantial 


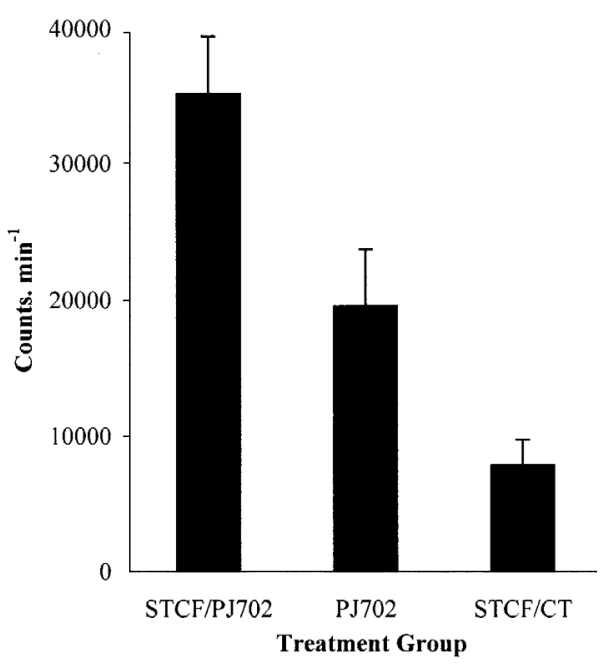

Figure 1. Average proliferation for spleen lymphocytes stimulated with STCF. Values are mean $(n=4)$. Error bars depict standard deviation. Group 1 = STCF/PJ702; Group 2 = PJ702; Group $3=\mathrm{STCF} / \mathrm{CT}$.

research has focused on the selection of protective antigens for subunit vaccines [4]. In this case as we were interested in the efficacy of the adjuvant, not the vaccine, and used $M$. tuberculosis STCF protein as the antigen. Previous studies have demonstrated that the STCF proteins released from the dividing bacteria generally induce higher levels of immune protection than killed cells alone [34], and are recognised universally as a potential source of antigens for a new TB vaccine [37].

The results of this study in respect to Tcell response are difficult to interpret due to the lack of a non-stimulated control group, and as such should be considered preliminary findings. What is significant in this study is that it does suggest that when compared to CT, PJ702 does show potential as an oral adjuvant. A direct comparison of the proliferation results between Group 1 and Group 3 (Fig. 1), whose treatments differ only in the type of adjuvant given, demonstrates the potentially effective immune stimulating properties of PJ702. Group 2 given only PJ702, also produced a significantly higher proliferation than Group 3, but this was significantly lower than Group 1 . Cholera toxin is amongst one of the strongest known mucosal adjuvants [9] and from this experiment an explanation cannot be identified for the low proliferation levels seen in Group 3 compared with Group 2. A likely reason is it is possible that conserved bacterial proteins exits between propionibacteria and mycobacteria. This may have lead to spleen cell activation in Group 2 by antigens similar, or the same as, the TB antigens used in the proliferation. Current studies using specific antigens rather than protein mixes are likely to provide a better understanding of the response generated.

\subsection{Cytokine analysis}

The type of immune response induced by a vaccine is crucial to TB immunity, as the incorrect immune response (Th2) has been found to be ineffective in controlling TB and actually illicit a disease exacerbating effect [23]. Th1 responses are characterised by secretion of IL-2 and IFN- $\gamma$ [21], and efficient protection from TB requires the induction of a potent Th1 response with high levels of IFN- $\gamma[2,11]$.

In this study the measurement of cytokines was undertaken purely to determine the type of T-cell response generated. All results across all vaccine groups showed that IFN- $\gamma$ was between 2 to 3 log higher than IL-4 levels (Fig. 2), suggesting a Th1 response. The IFN- $\gamma$ response for Group 3 was significantly higher than both Groups 1 and 2. This result may suggest that CT is a better immune stimulator than PJ702, but does not identify whether or not the enhanced IFN- $\gamma$ will improve the actual protective immunity to TB. As previous studies have shown that oral vaccines typically induce a Th2 response [10], these results give new potential to oral TB vaccine development, and warrant more extensive challenge studies to determine the protective value of such a vaccine using PJ702 as the adjuvant.

\section{CONCLUSION}

Oral vaccination against TB to date has been considered unachievable. This research 


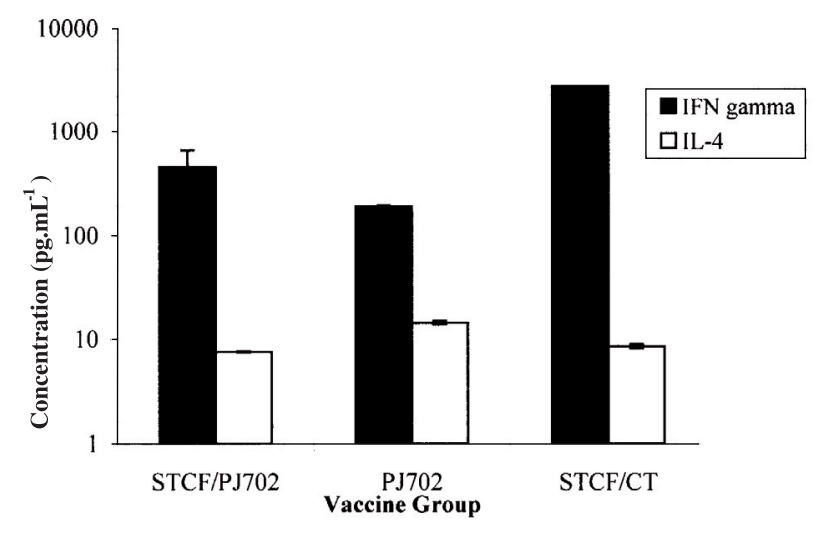

Figure 2. Comparison of IFN gamma and IL-4 levels between vaccine groups. Values are mean $(n=2)$. Error bars depict standard deviation. Group 1 = STCF/PJ702; Group 2 = PJ702; Group 3 = STCF/CT. suggests that efficiency of oral vaccination may be improved by selection of the appropriate adjuvant. Although immune stimulating ability of dairy propionibacteria is not new concept, their application as living vaccine vectors has not been fully investigated. Experience, primarily with lactobacilli, has shown however, that the potential of a probiotic to be used as vaccine vector is strain specific. Although preliminary, the studies presented here with PJ702 suggest that this strain of dairy propionibacteria may have application as a living vaccine vector for not only $\mathrm{TB}$, but a range of mucosally transmitted diseases. To identify this potential, further studies need to be undertaken.

\section{REFERENCES}

[1] Adams M.C., Huang Y., Kotula L., Blake R.J., Garg M.L., The efficacy of a potential new probiotic, Propionibacterium jensenii 702 , to correct vitamin B12 levels in an in vivo deficient animal model, Asia Pac. J. Clin. Nutr. 26 (2002) 261.

[2] Agger E.M., Anderson P., Tuberculosis subunit vaccine development: on the role of interferon- $\gamma$, Vaccine 19 (2001) 2298-2302.

[3] Aldwell F.E., Tucker I.G., de Lisle G.W., Buddle B.M., Oral delivery of Mycobacterium bovis $\mathrm{BCG}$ in a lipid formulation induces resistance to pulmonary tuberculsois in mice, Infect. Immunity 71(2003) 101-108.
[4] Anderson P., TB vaccines: progress and problems, Trends Immunol. 22 (2001) 160-168.

[5] Anderson P., Askard D., Ljungqvist L., Bentzon M.W., Heron I., T-cell proliferative response to antigens secreted by Mycobacterium tuberculosis, Infect. Immunology 59 (1991) 1558-1563.

[6] Brandt L., Cunha J.F., Olsen A.W., Chilima B., Hirsch P., Appelberg R., Andersen P., Failure of Mycobacterium bovis BCG vaccine: some species of environmental mycobacteria block multiplication of $\mathrm{BCG}$ and induction of protective immunity to tuberculosis, Infect. Immunity 70 (2002) 672-678.

[7] Charteris W.P., Kelly P.M., Morelli L., Collins J.K., Development and application of an in vitro methodology to determine the transit tolerance of potentially probiotic Lactobacillus and Bifidobacterium species in the upper human gastrointestinal tract, J. Appl. Microbiol. 84 (1998) 759-768.

[8] Conway P.L., Gorbach S.L., Goldin B.R., Survival of lactic acid bacteria in the human stomach and adhesion to intestinal cells, J. Dairy Sci. 70 (1987) 1-12.

[9] Del Giudice G., Podda A., Rappuoli R., What are the limits of adjuvanticity?, Vaccine 20 (2002) S38-S41.

[10] Doherty M.T., Olsen A.W., Van Pinxteren L., Andersen P., Oral vaccination with subunit vaccines protects animals against aerosol infection with Mycobacterium tuberculosis, Infect. Immunity 70 (2002) 3111-3121.

[11] Elhay M.J., Anderson P., Immunological requirements for a subunit vaccine against tuberculosis, Immunol. Cell Biol. 75 (1997) 595603. 
[12] Erickson K.L., Hubbard N.E., Probiotic immunomodulation in health and disease, J. Nutr. 130 (2000) 403S-409S.

[13] Famularo G., Moretti S., Marcellini S., De Simone C., Stimulation of immunity by probiotics, in: Fuller R. (Ed.), Probiotics 2: Applications and practical aspects, Chapman and Hall, London, UK, 1997, pp. 133-161.

[14] Fatkenheuer G., Taelman H., Lepage P., Schwenk A., Wenzel R., The return of tuberculosis, Diag. Microbiol. Infect. Dis. 34 (1999) 139-146.

[15] Flaminio M.J.B.F., Rush B.R., Shuman W., Immunologic function in horses after nonspecific immunostimulant administration, Vet. Immunol. Immunopath. 63 (1998) 303-315.

[16] Gheorghiu M.R., Lagranderie M., Balazuc A.M., Stabilisation of BCG vaccines. New approaches to stabilisation of vaccine potency, Dev. Biol. Stand. 87 (1996) 251-261.

[17] Guerin N., Evaluation of BCG and new vaccines against tuberculosis, Pediat. Pulm. S16 (1997) 286-287.

[18] Huang Y., Adams M.C., An in vitro model for investigating intestinal adhesion of potential dairy propionibacteria probiotic strains using cell line C2BBe1, Lett. Appl. Microbiol. 36 (2003) 213-216.

[19] Huang Y., Adams M.C., In vitro assessment of the upper gastrointestinal tolerance of potential probiotic dairy propionibacteria, Int. J. Food Microbiol. 91 (2004) 253-260.

[20] Huang Y., Kotula L., Adams M.C., The in vivo assessment of safety and gastrointestinal survival of an orally administered novel probiotic, Propionibacterium jensenii 702, in a male Wistar rat model, Food Chem. Toxicol. 41 (2003) 1781-1787.

[21] Kaufmann S.H.E., Anderson P., Immunity to mycobacteria with emphasis on tuberculosis: implications for rational design of an effective tuberculosis vaccine, Chem. Immunol. 70 (1998) 21-59.

[22] Kaufmann S.H.E., Hess J., Immune response against Mycobacterium tuberculosis: implications for vaccine development, J. Biotechnol. 83 (2000) 13-17.

[23] Linbald D.B., Elhay M.J., Silva R., Appelberg R., Anderson P., Adjuvant modulation of immune responses to tuberculosis subunit vaccines, Infect. Immunity 65 (1997) 623-629.

[24] Marin M.L., Tejada-Simon M.V., Lee J.H., Murtha J., Ustunol Z., Pestka J.J., Stimulation of cytokine production in clonol macrophage and T-cell models by Streptococcus thermophilus: comparison with Bifidobacte- rium sp. and Lactobacillus bulgaricus, J. Food Prot. 61 (1998) 859-864.

[25] Megid J., Peraçolli M.T.S., Curi P.R., Zanetti C.R., Cabrera W.H., Vassao R., Ito F.H., Effect of the Bacillus of Calmette-Guérin, Propionibacterium acnes and avridine as immunomodulators in antirabies vaccination of mice using the Fuenzalida-Palacios mouse brain vaccine, Vaccine 17 (1999) 24462452.

[26] Megid J., Kaneno R., Nozaki C.N., Broto C.J.C., Almeida M.F., Increased interleukin10 associated with low IL-6 concentration correlated with greater survival rates in mice infected by rabies virus vaccinated against it and immunomodulated with $P$. acnes, Comp. Immunol. Microbiol. Infect. Dis. 27 (2004) 393-411.

[27] Miettinen M., Matikainen S., Vuopio-Varkila J., Pirhonen J., Varkila K., Kurimoto M., Julkunen I., Lactobacilli and streptococci induce interleukin-12 (IL-12), IL-18 and gamma interferon production in human peripheral blood mononuclear cells, Infect. Immunity 66 (1998) 6058-6062.

[28] Murray P.J., Defining the requirements for immunological control of mycobacterial infections, Trends Microbiol. 7 (1999) 366-372.

[29] Murray C.J.L., Salomon J.A., Modeling the impact of global tuberculosis strategies, Proc. Natl. Acad. Sci. USA. 95 (1998) 1388113886.

[30] Pouwels P.H., Leer R.J., Shaw M., Heijne den BakGlashouwer M., Tielen F.D., Smit E., Martinez B., Jore J., Conway P.L., Lactic acid bacteria as antigen delivery vehicles for oral immunisation purposes, Int. J. Food Microbiol. 41 (1998) 155-167.

[31] Richter L., Kipp P.B., Transgenic plants as edible vaccines, Curr. Top. Microbiol. Immunol. 240 (1999) 159-176.

[32] Russell-Jones G.J., Oral vaccine delivery, J. Control. Release 65 (2000) 49-54.

[33] Seeger J.F.M.L., Lactobacilli as live vaccine delivery vectors: progress and prospects, Trends Biotechnol. 20 (2002) 508-515.

[34] Skjot R.L.V., Oettinger T., Rosenkrands I., Ravn P., Brock I., Jacobsen S., Anderson P., Comparative evaluation of low-molecularmass proteins from Mycobacterium tuberculosis identifies members of the ESAT-6 family as immunodominant T-cell antigens, Infect. Immunity 68 (2000) 214-220.

[35] Wang X., Brown I.L., Evans A.J., Conway P.L., The protective effects of high amylase maize (amylomaize) starch granules on the survival of Bifidobacterium sp. in the mouse 
intestinal tract, J. Appl. Microbiol. 87 (1999) 631-639.

[36] Waterman S.R., Small P.L.C., Acid-sensitive enteric pathogens are protected from killing under extremely acidic conditions of $\mathrm{pH} 2.5$ when they are inoculated onto certain solid food sources, Appl. Environ. Microbiol. 64 (1998) 3882-3886.

[37] Weldingh K., Andersen P., Immunological evaluation of novel Mycobacterium tuberculosis culture filtrate proteins, FEMS Immunol. Microbiol. 23 (1999) 159-164.
[38] World Health Organisation, Tuberculosis control and research strategies for the 1990's: memorandum from a WHO meeting, Bull. WHO 70 (1992) 17-21.

[39] World Health Organisation, The global health emergency, WHO report on the TB epidemic, Geneva Switzerland, 1994.

[40] Zarate G., Perez-Chaia A., Gonzalez S., Oliver G., Viability and B-galactosidase activity of dairy propionibacteria subjected to digestion by artificial gastric and intestinal fluids, J. Food Prot. 63 (2000) 1214-1221. 